\title{
ASPECTOS FITOGEOGRÁFICOS DA BACIA HIDROGRÁFICA DO ARROIO LAJEADO GRANDE, RS - BRASIL. 4 - FLORESTAS DE GALERIA E CAPÕES-DE-MATO ${ }^{1}$
}

\author{
FABIANO DA SILVA ALVES ${ }^{2}$ JOSÉ NEWTON CARDOSO MARCHIORI $^{3}$ \\ LUIS EDUARDO DE SOUZA ROBAINA ${ }^{4}$
}

\section{RESUMO}

Duas tipologias florestais foram reconhecidas na bacia hidrográfica do arroio Lajeado Grande, oeste do Rio Grande do Sul: florestas de galeria e capões-de-mato. São definidas as espécies componentes, em ambas as tipologias, e apresentadas as respectivas áreas de distribuição em mapa fitogeográfico.

Palavras-chave: Fitogeografia, Rio Grande do Sul, arroio Lajeado Grande, florestas de galeria, capões-demato.

\section{ABSTRACT}

[Phytogeographic features in the basin of Lajeado Grande stream, Rio Grande do Sul state Brazil. 4 - Gallery forests and small forest patches].

They were recognized two forest types in Lajeado Grande stream basin, west of Rio Grande do Sul state, Brazil: gallery forests and small patches of forest. The component species of these types of vegetation are furnished, being the distribution areas presented in a phytogeographic map.

Key words: Phytogeography, Rio Grande do Sul state - Brazil, Lajeado Grande stream, gallery forests, small patches of forest.

\section{INTRODUÇÃO}

O oeste do Rio Grande do Sul carece de estudos detalhados sobre a composição florística, distribuição geográfica e vinculações entre vegetação natural e meio físico. Frente esta situação - e com o interesse de contribuir para o avanço do conhecimento científico, bem como alertar sobre a necessidade de preservação da biodiversidade e conservação de paisagens naturais significativas no Estado -, o presente trabalho visa a identificar, caracterizar e mapear

\footnotetext{
1 Extraído de "Estudos fitogeográficos na bacia hidrográfica do arroio Lajeado Grande - Oeste do RS", Dissertação de Mestrado defendida por ALVES (2008), no Programa de Pós-Graduação em Geografia - UFSM. Apoio: FAPERGS - Procorede III - 0614357.

2 Prof., MSc. Universidade da Região da Campanha URCAMP - Alegrete, RS.

3 Prof., Dr. Programa de Pós-Graduação em Engenharia Florestal - UFSM. Bolsista de Produtividade em Pesquisa (CNPq - Brasil).

4 Prof., Dr. Programa de Pós-Graduação em Geografia UFSM.
}

as florestas de galeria ${ }^{5}$ e capões-de-mato ${ }^{6}$ da bacia hidrográfica do arroio Lajeado Grande, com base em aspectos fisionômicos, florísticos e fitoecológicos.

\section{MATERIAIS E MÉTODOS}

Tributário do rio Ibicuí, a bacia do arroio Lajeado Grande situa-se no oeste do Rio Grande do Sul, em área dos municípios de Alegrete e Manoel Viana, entre as coordenadas geográficas de $55^{\circ} 20^{\prime} 28^{\prime \prime}$ e $55^{\circ} 36^{\prime} 42^{\prime \prime}$ de longitude oeste, e $29^{\circ} 36^{\prime} 20^{\prime \prime}$ e 29 $59^{\circ}$ ' 52' de latitude sul

\footnotetext{
5 Segundo RODRIGUES \& LEITÃO-FILHO (2000), o termo 'Floresta de Galeria' deve ser usado em substituição ao termo 'Mata ciliar' somente em regiões onde a vegetação de interflúvio não é florestal.

○ O termo "capão", de origem indígena (Tupinambá), deriva de "caa-apoam" e significa mata circular. É utilizado regionalmente para caracterizar ilhas de vegetação silvática dispersas em áreas campestres. Este termo foi registrado pelos portugueses com a corruptela "capão de mato" (MARCHIORI, 2004).
} 


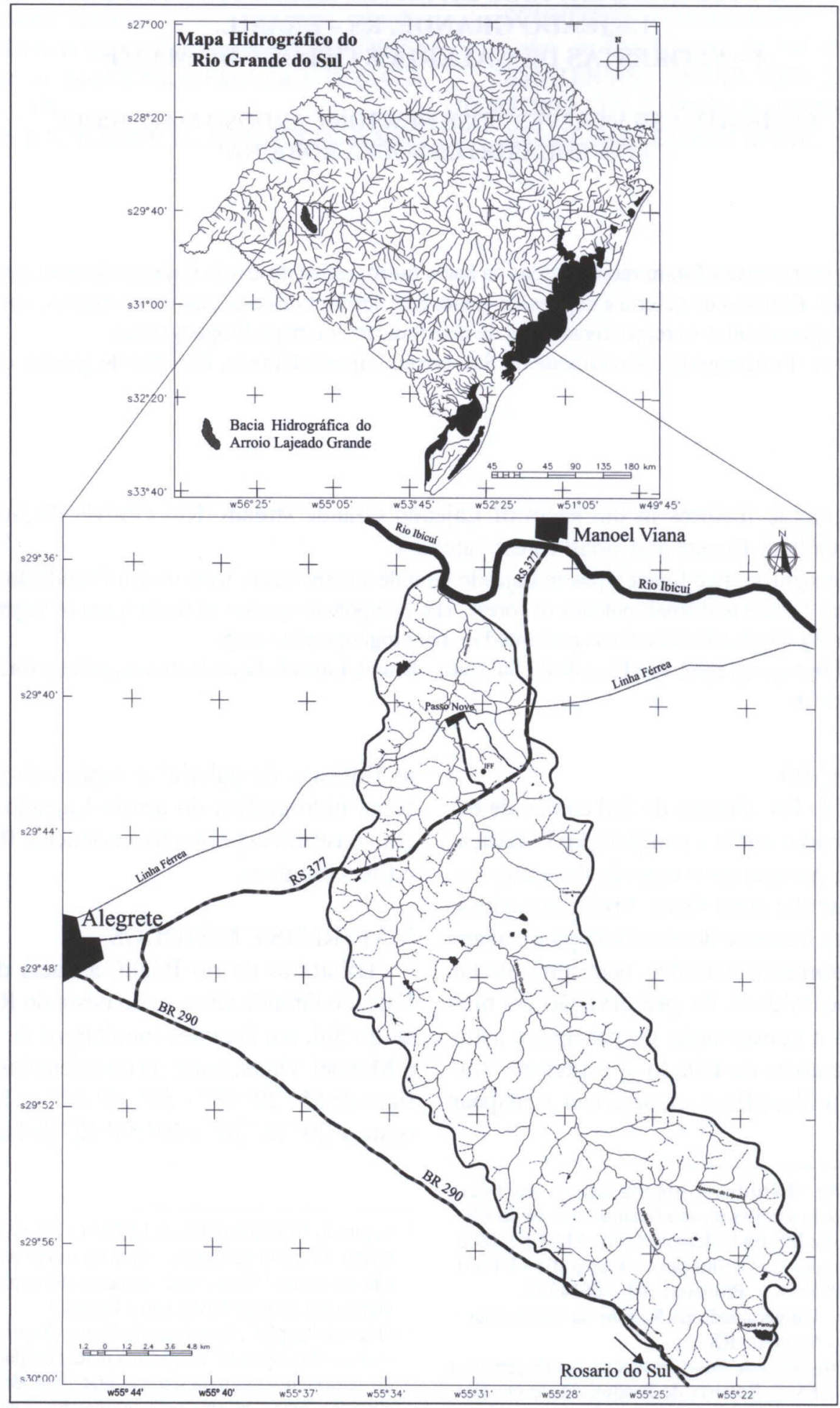

FIGURA 1 - Mapa de localização da bacia hidrográfica do Arroio Lajeado Grande, Alegrete - RS. 
(Figura 1). De sua variada vegetação, o presente trabalho trata das florestas de galeria e dos capões-de-mato, tendo sido usada, para a sua identificação, caracterização e mapeamento, a metodologia a seguir discriminada.

As áreas de ocorrência das florestas de galeria e capões-de-mato foram inicialmente reconhecidas com base em aspectos fisionômicos. O mapeamento das mesmas, por sua vez, foi definido a partir do mapa morfolitológico apresentado em artigo anterior ${ }^{7}$, com o auxílio de imagens de satélite (ETM Landsat, do Google Earth) e complementado por observações in loco.

Na sequência, foram realizados levantamentos florísticos detalhados em áreas com baixos índices de alteração antrópica, com o uso de ficha de inventário fitogeográfico proposta por Bertrand (1966), constante em Passos (2003). Além de informações gerais (local, data e pesquisadores), foram anotados aspectos relativos à fisionomia da vegetação na área amostral, bem como sua localização geográfica (coordenadas), identificação botânica das espécies e aspectos do meio físico (recursos hídricos, relevo, solos, etc.). A identificação das espécies vegetais, realizada inicialmente a campo, teve a amostragem encerrada, em cada tipologia, com base na curva do coletor.

Para todas as espécies não identificadas a campo foi coletado material vegetativo e/ou reprodutivo, visando posterior análise em laboratório, com o auxílio de bibliografia especializada.

O levantamento de dados do meio físico possibilitou a realização de uma análise fitoecológica, de modo que as tipologias, definidas inicialmente sob os pontos de vista fisionômico e florístico, foram também caracterizadas com base nos hábitats de ocorrência, bem como georreferenciadas e sobrepostas ao mapa morfolitológico. A sobreposição cartográfica destas informações levou ao reconhecimento e

${ }^{7}$ ALVES, F. S.; ROBAINA, L. E. S.; MARCHIORI, J. N.C. Aspectos fitogeográficos da bacia hidrográfica do arroio Lajeado Grande, RS - Brasil. 1 - O meio físico. Balduinia, Santa Maria, n. 18, p. 1 - 9, 2009. caracterização precisa das tipologias, bem como de seus respectivos hábitats preferenciais.

A caracterização e mapeamento destas unidades, somadas à base cartográfica do mapa morfolitológico, levou, com a utilização dos softwares GTM PRO versão 4.6 (SIG) e Corel Draw X3 (edição gráfica), à elaboração do mapa fitogeográfico com as áreas de ocorrência das duas tipologias de vegetação natural, objeto do presente trabalho.

\section{DESCRIÇÃO DAS TIPOLOGIAS}

Apesar das marcas evidentes de antropismo, observadas em grande parte da bacia do arroio Lajeado Grande, o reconhecimento de distintas tipologias de vegetação tornou-se possível graças à análise integrada de aspectos fisionômicos, florísticos e fitoecológicos. A Figura 2 apresenta a distribuição geográfica das florestas de galeria e dos capões-de-mato, caracterizadas a seguir:

\section{1 - Floresta de galeria}

A floresta de galeria ou mata ciliar é a principal formação de caráter florestal na bacia hidrográfica em estudo. Associada, intimamente, à planície de acumulação, tais florestas distinguem-se das demais tipologias, sob o ponto de vista fisionômico, estendendo-se ao longo da drenagem principal e de alguns afluentes de maior porte, como faixas de largura e composição florística variada, segundo particularidades locais. Ao longo do leito do arroio Lajeado Grande, as matas ciliares se estendem por mais de 60 quilômetros de extensão, ramificando-se em alguns de seus afluentes (Figura 3). Em muitos pontos, todavia, a faixa florestal encontra-se interrompida e/ou segmentada, exibindo, por vezes, sinais visíveis da ação antrópica.

No contato direto com a água, o grupo das reófitas $^{8}$ inclui o sarandi (Sebastiania schottiana

${ }^{8}$ Espécies vegetais morfologicamente adaptadas a condições severas, próprias da margem dos cursos d'água. Entre outros aspectos restritivos, tais plantas precisam suportar submersão temporária, bem como a força da água, por ocasião de enchentes (MARCHIORI, 2000, p. 229). 


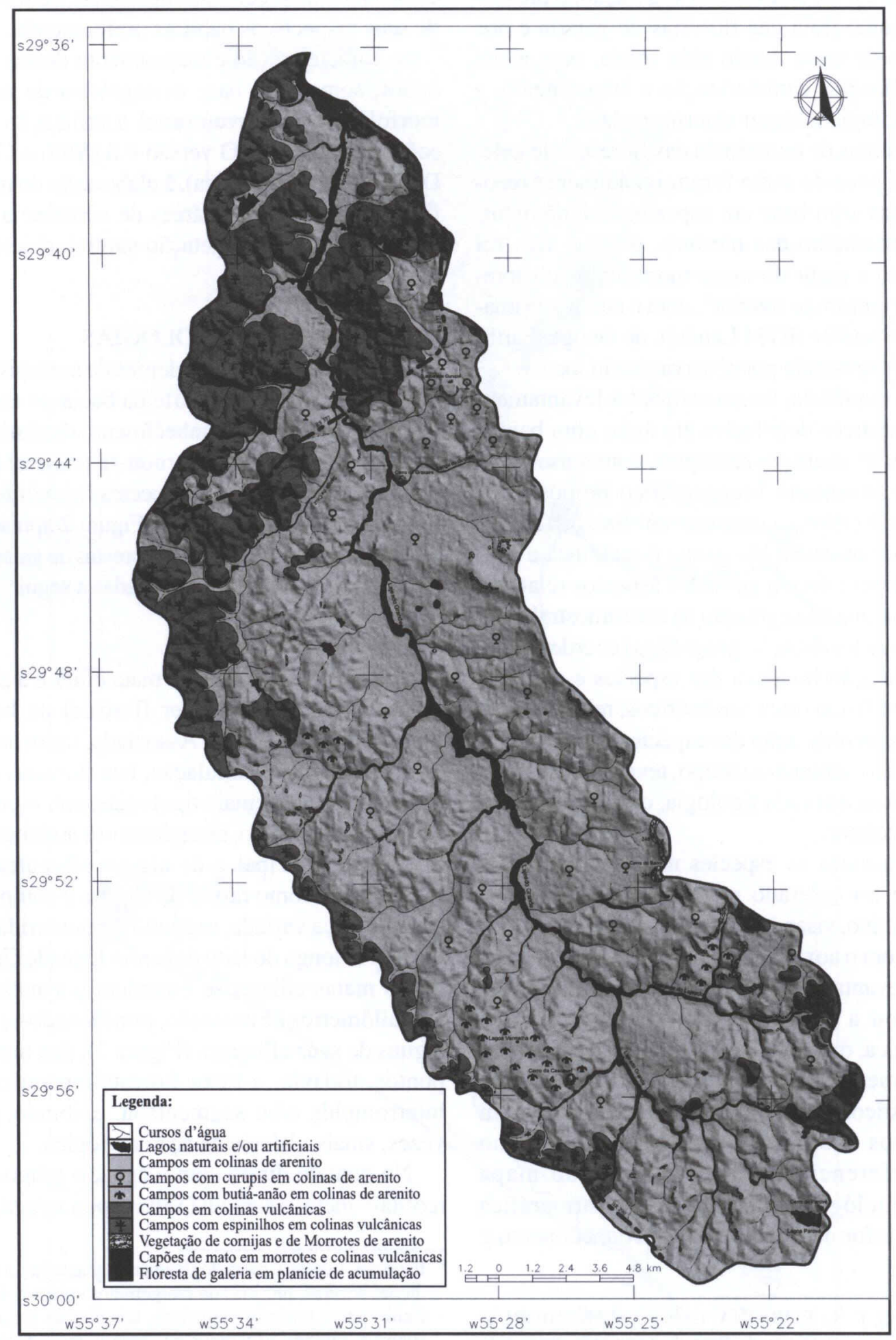

FIGURA 2 - Mapa fitogeográfico da bacia hidrográfica do Arroio Lajeado Grande, Alegrete - RS. 


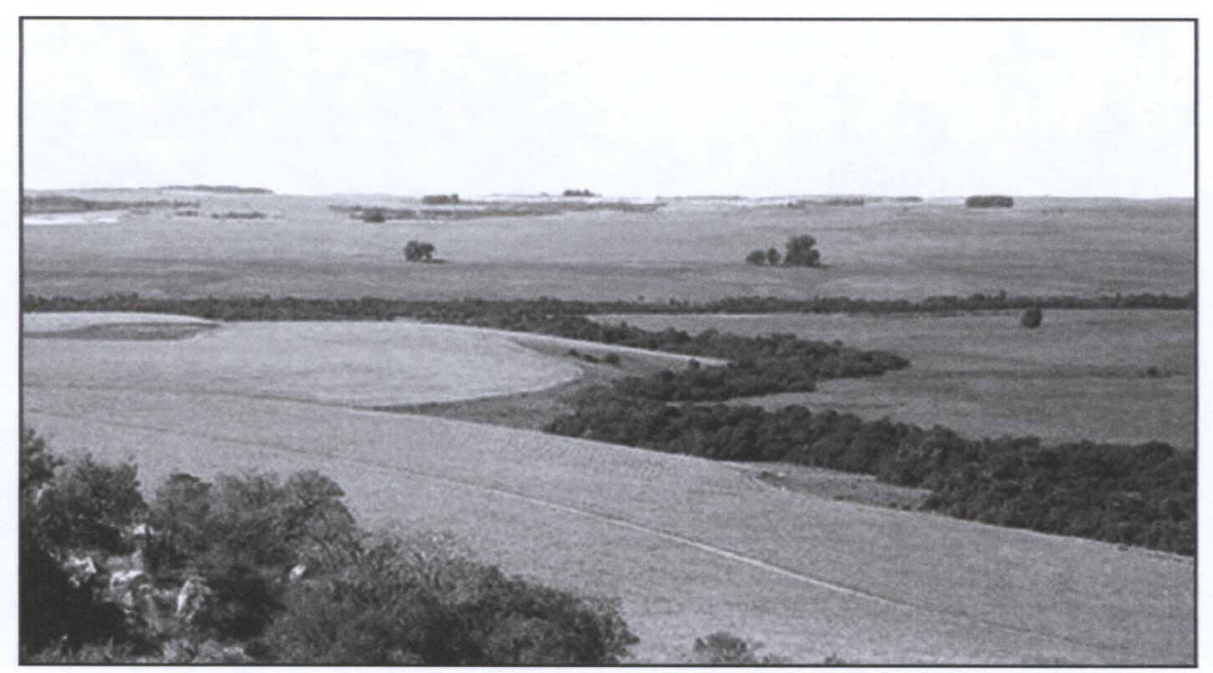

FIGURA 3 - Vista parcial da mata ciliar do Arroio Lajeado Grande.

(Müll. Arg.) Müll. Arg.), espécie mais representativa desta comunidade, bem como o sarandivermelho (Phyllantus sellowianus (Klotzsch) Müll.Arg.), o sarandi-mata-olho (Pouteria salicifolia (Spreng.) Radlk.), o angiquinho (Calliandra tweedii Benth.), o salseiro (Salix humboldtiana Willd.) e, por vezes, o juquiri (Mimosa incana (Spreng.) Benth.) (Figura 4).

$\mathrm{Na}$ floresta propriamente dita, destacam-se: o coqueiro-gerivá (Syagrus romanzoffiana (Cham.) Glassman) (Figura 5), o branquilho (Sebastiana commersoniana (Baill.) L.B. Sm. \& Downs), o branquilho-leiteiro (Sebastiana brasiliensis Spreng.), a corticeira-do-banhado (Erythrina cristagalli L.), a murta (Blepharocalyx salicifolius (Kunth) O. Berg), a pitangueira (Eugenia uniflora L.), o pessegueiro-bravo (Prunus myrtifolia (L.) Urb.), o chalchal (Allophylus edulis (A.St.-Hil., Cambess.\& A. Juss.) Radlk.), o camboatá-branco (Matayba elaeagnoides Radlk.), o camboatá-vermelho (Cupania vernalis Cambess.), o tarumã-preto (Vitex megapotamica (Spreng.) Moldenke), o angico-vermelho (Parapiptadenia rigida (Benth.) Brenan), o açoita-cavalo (Lueha divaricata Mart. \& Zucc.), o camboim (Myrcia selloi (Spreng.) N. Silveira), o marmeleiro-domato (Ruprechtia laxiflora Meisnn.), o taquaruçu (Guadua trinii (Ness) Ness ex. Rupr.), o coentrilho (Zanthoxylum fagara (L.) Sarg.), a mamica-de-cadela (Zanthoxylum rhoifolium Lam.), a carne-de-vaca (Styrax leprosus Hook. \& Arn.), o guamirim (Myrcia palustris DC.), a capororoca (Myrsine laetevirens (Mez) Arechav.), a canela-preta (Nectandra megapotamica (Spreng.) Mez) e a canela-lageana (Ocotea pulchella (Nees) Mez). No sub-bosque, salienta-se a embira (Daphnopsis racemosa Griseb.), por sua abundância (Figura 5). Ao longo de sua extensão, também não são raros na mata ciliar: o sucará (Xylosma tweediana (Clos.) Eichler), as capororocas (Myrsine coriacea (Sw.) R.Br.; Myrsine lorentziana (Mez) Arechav.), a guabiroba-do-mato (Campomanesia xanthocarpa O.Berg), o guamirim (Eugenia uruguayensis Cambess.), o araçá-domato (Myrcianthes cisplatensis (Cambess.) O.Berg.), a laranjeira-do-banhado (Citronella gongonha (Mart.) R.A. Howard.), a congonha (Citronella paniculata (Mart.) R.A. Howard.), o esporão-de-galo (Strychnos brasiliensis (Spreng.) Mart.), o pau-de-junta (Coccoloba cordata Cham.), o araticum-folha-de-salso (Annona neosalicifolia (Schlecht.) Rainer) e o araticum-quaresma (Annona emarginata (Schlecht.) Rainer).

De modo geral, a orla da floresta de galeria reúne um conjunto de arbustos, árvores pionei- 


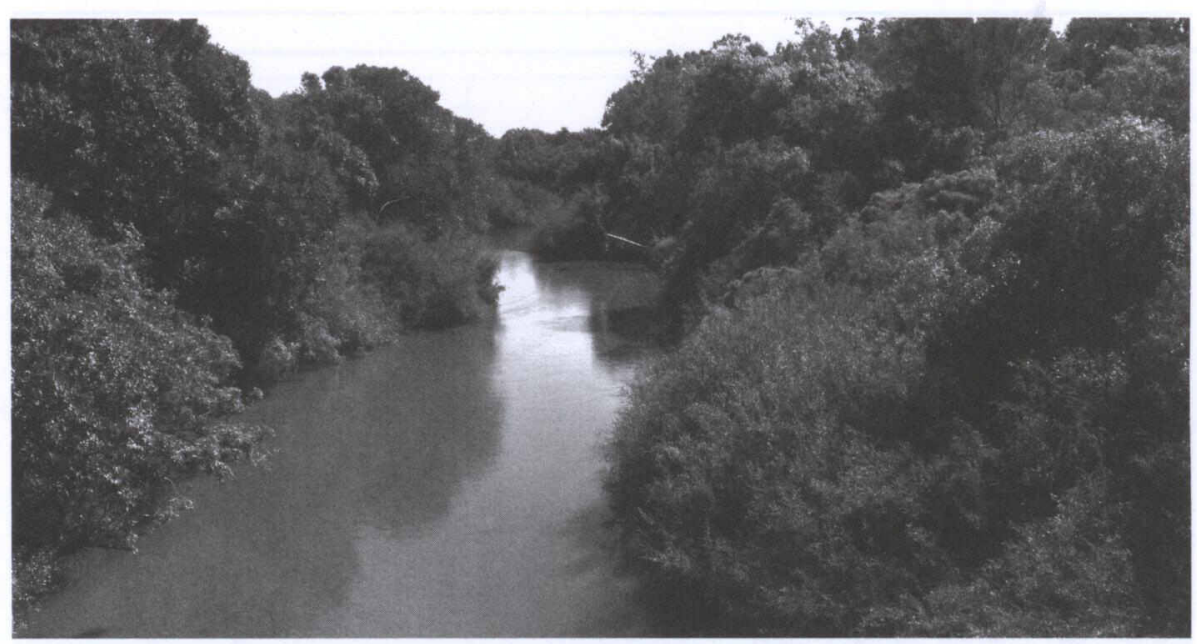

FIGURA 4 - Aspecto geral da vegetação reofítica, nas margens do Arroio Lajeado Grande.

ras e lianas, todas heliófilas ${ }^{9}$, das quais salientam-se: a aroeira-brava (Lithraea molleoides (Vell.) Engl.), o molho (Schinus polygamus (Cav.) Cabrera), a cancorosa (Maytenus muelleri Schwacke), o veludinho (Guettarda uruguensis Cham. \& Schltdl.), o aguaí-vermelho (Chrysophyllum marginatum (Hook. \& Arn.) Radlk.), o cambará (Gochnatia polymorpha (Less.) Cabrera), as taleiras (Celtis iguanea (Jacq.) Sarg.; Celtis ehrenbergiana (Klotzsch) Liebm.), a unha-de-gato (Acacia bonariensis Gill. ex Hook. \& Arn.), a pixirica (Miconia hyemalis A. St.-Hil. \& Naudin), a viuvinha (Chomelia obtusa Cham. \& Schltdl.), o chá-de-bugre (Casearia sylvestris Sw.), a sete-sangrias (Symplocus uniflora (Pohl) Benth.), a japecanga (Smilax campestris Griseb.) e a embira (Daphnopsis racemosa Griseb.). A aroeira-cinzenta (Schinus lentiscifolius Marchand.) e a tuna (Cereus hildmannianus K. Schum.), por sua vez, são menos freqüentes.

Em áreas com planície de acumulação reduzida, a floresta de galeria conecta-se, não raro, a capões-de-mato localizados à meia encosta de colinas e morrotes vulcânicos, bem como à ve-

9 Plantas exigentes de luz, capazes de ocupar áreas desnudas (MARCHIORI, 2007). getação de cornijas e morrotes de arenito. Tais contatos podem contribuir com diferentes espécies a sua composição florística, notadamente de elementos típicos da orla florestal: é o caso do espinilho (Vachellia caven (Molina) Seigler \& Ebinger) e do garupá (Aloysia gratissima (Hook.) Tronc.), elementos típicos de colinas e morrotes com substrato vulcânico, bem como do curupi (Sapium haematospermum Müll. Arg.) e do jasmim-catavento (Tabernaemontana catharinensis DC.), no caso de colinas com substrato arenítico.

\section{2 - Capões-de-mato}

Núcleos florestais de pequena extensão, os capões-de-mato ocorrem dispersos em meio à vegetação campestre, apresentando composição florística semelhante à floresta de galeria. Dispostos à meia encosta de colinas e morrotes de substrato vulcânico, os capões-de-mato estão geralmente associados a drenagens de primeira ou segunda ordem, ocorrendo em locais de declividades acentuadas e/ou com amplitudes relativamente elevadas (Figura 6).

Na composição dos capões, salientam-se, como espécies características: a aroeira-brava (Lithraea molleoides (Vell.) Engl.), o branquilho (Sebastiana commersoniana (Baill.) L.B. Sm. \& Downs), o camboatá-vermelho (Cupania 


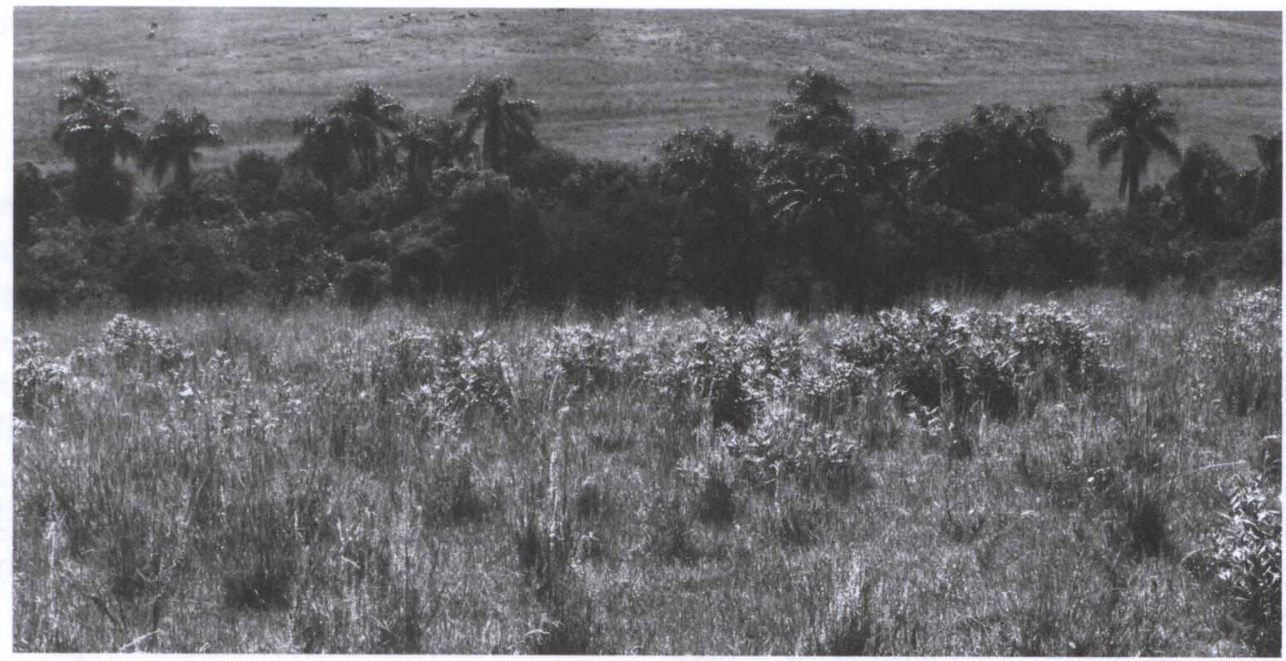

FIGURA 5 - Contraste da mata ciliar, com gerivás, e vegetação campestre adjacente.

vernalis Cambess.), a carne-de-vaca (Styrax leprosus Hook. \& Arn.), o coentrilho (Zanthoxylum fagara (L.) Sarg.), a mamica-de-cadela (Zanthoxylum rhoifolium Lam.), o pessegueiro-bravo (Prunus myrtifolia (L.) Urb.) e o chal-chal (Allophylus edulis (A. St.-Hil., Cambess.\& A. Juss.) Radlk.).

Por vezes, algumas espécies de ocorrência eventual apresentam freqüência significativa nos capões-de-mato. É o caso do tarumã-de-espinho (Citharexylum montevidense (Spreng.)
Moldenke), do angico-vermelho (Parapiptadenia rigida (Benth.) Brenan), do açoita-cavalo (Luehea divaricata Mart. \& Zucc.), da capororoca (Myrsine laetevirens (Mez) Arechav.), do cambará (Gochnatia polymorpha (Less.) Cabrera), da figueira-do-mato (Ficus luschnathiana (Miq.) Miq.), do guabijú (Myrcianthes pungens (O.Berg) D. Legrand), da murta (Blepharocalyx salicifolius (Kunth) O.Berg), do camboatá-branco (Matayba elaeagnoides Radlk.), do esporão-de-galo

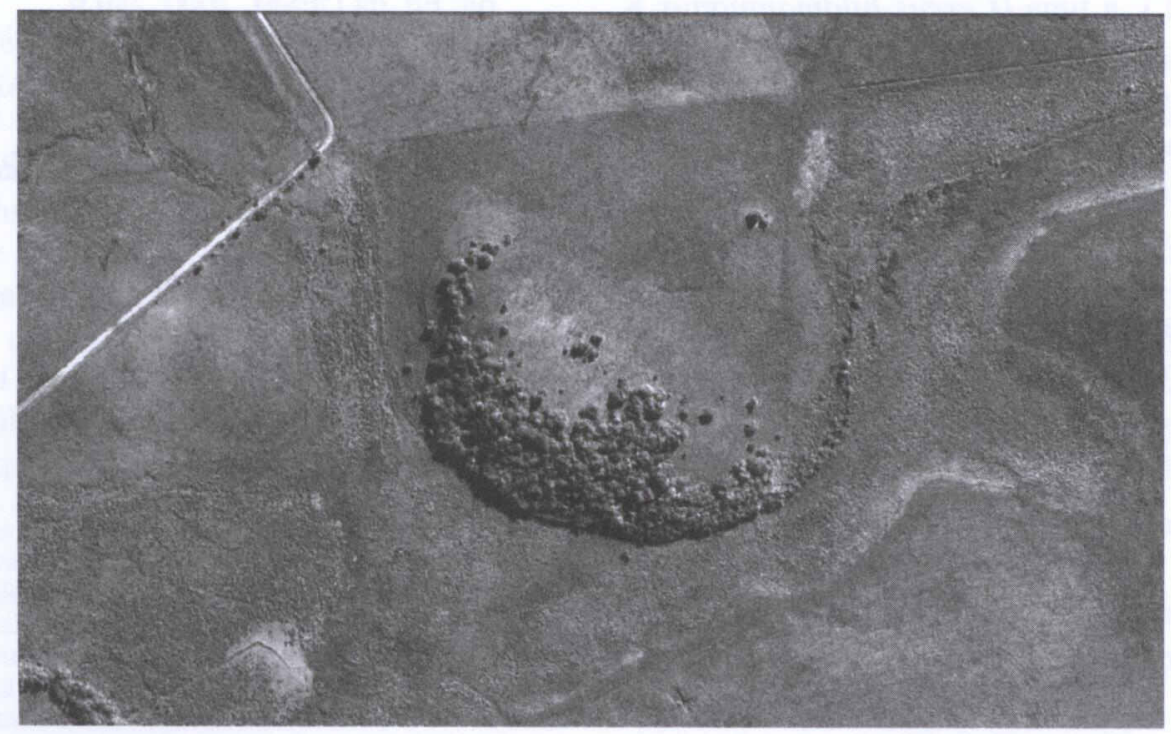

FIGURA 6 - Capão-de-mato, em encosta de colina de substrato vulcânico (fonte: Google Earth, 2008). 
(Strychnos brasiliensis (Spreng.) Mart.), da canela-preta (Nectandra megapotamica (Spreng.) Mez), da canela-guaicá (Ocotea puberula (Rich.) Nees.), da canela-lajeana (Ocotea pulchella (Nees) Mez), do branquilho-leiteiro (Sebastiana brasiliensis Spreng.), do coqueirogerivá (Syagrus romanzoffiana (Cham.) Glassman), da laranjeira-do-banhado (Citronella gongonha (Mart.) R.A. Howard.) e da corticeirado-banhado (Erythrina cristagalli L.).

Como núcleos avançados de floresta em meio ao campo nativo, os capões reúnem contingente expressivo de arbustos, lianas e arvoretas pioneiras e heliófilas em sua orla, destacando-se: o espinilho (Vachellia caven (Molina) Seigler \& Ebinger), o garupá (Aloysia gratissima (Hook.) Tronc.), o molho (Schinus polygamus (Cav.) Cabrera), a coronilha (Scutia buxifolia Reiss.), a cancorosa (Maytenus muelleri Schwacke), a taleira (Celtis iguanea (Jacq.) Sarg.), a viuvinha (Chomelia obtusa Cham. \& Schltdl.), o veludinho (Guettarda uruguensis Cham. \& Schlecht.), a pitangueira (Eugenia uniflora L.), o chá-de-bugre (Casearia sylvestris $\mathrm{Sw}$.), a embira (Daphnopsis racemosa Griseb.) e a japecanga (Smilax campestris Griseb.). De ocorrência eventual, citam-se: a aroeira-cinzenta (Schinus lentiscifolius Marchand.), a tuna (Cereus hildmannianus $\mathrm{K}$. Schum.), a anacauíta (Schinus molle L.), o aguaívermelho (Chrysophyllum marginatum (Hook. \& Arn.) Radlk.), a timbaúva (Enterolobium contortisiliquum (Vell.) Morong) e a guajuvira (Cordia americana (L.) Gottschling \& J.E.Mill.).

Nos capões-de-mato associados a substrato vulcânico delgado, o afloramento de rochas areníticas a meia encosta torna-se comum, influindo diretamente na composição florística, que passa a incluir elementos típicos da vegetação de morrotes e cornijas de arenito.

\section{CONSIDERAÇÕES FINAIS}

Com pouco mais de $60 \mathrm{~km}$ de extensão ao longo do Arroio Lajeado Grande, as florestas de galeria ocupam uma área relativamente pequena no conjunto da bacia hidrográfica; os capões-de-mato, por sua vez, ocupam área ainda menor. A composição florística de ambas as tipologias, relativamente pobre no tocante à diversidade de elementos arbóreos, assemelha-se ao verificado em áreas correspondentes, no oeste do Estado.

\section{REFERÊNCIAS BIBLIOGRÁFICAS}

ALVES, F. S. Estudos fitogeográficos na bacia hidrográfica do Arroio Lajeado Grande, oeste do Rio Grande do Sul. Santa Maria: UFSM, 2008. 106 f. Dissertação (Programa de Pós-Graduação em Geografia e Geociências) - Universidade Federal de Santa Maria.

ALVES, F. S.; ROBAINA, L. E. S.; MARCHIORI, J. N. C. Aspectos fitogeográficos da bacia hidrográfica do arroio Lajeado Grande, RS Brasil. 1 - O meio físico. Balduinia, Santa Maria, n. 18, p. $1-9,2009$.

MARCHIORI, J. N. C. Dendrologia das Angiospermas: das Bixáceas às Rosáceas. Santa Maria: Ed. da UFSM, 2000. 240 p.

MARCHIORI, J. N. C. Fitogeografia do Rio Grande do Sul: Campos Sulinos. Porto Alegre: EST, 2004. $110 \mathrm{p}$.

MARCHIORI, J. N. C. Dendrologia das Angiospermas: Leguminosas. Santa Maria: Ed. da UFSM, 2007. 199 p.

PASSOS, M. M. Biogeografia e paisagem. Maringá: [s.n.], 2003. 264 p.

RODRIGUES, R. R.; LEITÃO FILHO, H. F. Matas Ciliares: Conservação e recuperação. São Paulo: Ed. da USP: Fapesp, 2000. 320 p. 